\title{
iSize - Implementation of International Anthropometric Survey Results for Worldwide Sizing and Fit Optimization in the Apparel Industry
}

\author{
Anke RISSIEK*, Rainer TRIEB \\ Human Solutions GmbH, Kaiserslautern (D), Germany
}

\begin{abstract}
In the recent two decades new anthropometric surveys have been conducted in several European countries as well as world wide. Although international standards for the documentation of anthropometrical surveys have been defined, incorporating up-to-date anthropometrical data into product design and product development processes still is an challenging and time consuming task. due to the lack of standardization cross the entire product development process, particularly with respect to application specific analysis and optimization tools.
\end{abstract}

iSize is a new and innovative online tool incorporating both, standardized data representation enabling analyses on combined and mixed target markets and appropriate, application specific functions enabling the user to directly solve typical tasks in his day to day work. Beneath standard statistical analyses iSize provides advanced functionality to optimize size tables with respect to user definable target markets, evaluation of market shares and capabilities to directly compare and evaluate different size table approaches within an easy-to-use online-portal.

iSize addresses the needs of various responsibilities cross the entire company: management is provided with quantitative facts for decision making in business development, sales people get the necessary numbers for sales planning and market potential estimation, product development is supported with precise body dimension data to optimize the fit of the garments and retail can put the right sizes and numbers of sizes into their shops according to their addressed target customers.

Keywords: 3D body scanning, anthropometric survey, sizing, fit optimization, apparel

\section{Introduction}

Anthropometric design is one of the most important disciplines within the area of ergonomic approaches. With the correct anthropometry layout, products and working tools can be used safely, comfortably and in a healthy manner. Particularly in the apparel branch creation of sizing systems is critical to the fit of the garments. Effective sizing systems have to take body dimensions and body proportions in a systematic way into account in order to optimally cover the target market with the right and well fitting sizes $[8,12,18]$.

In the recent decade 3D body scanning has become a standard technology for anthropometric surveys performed world wide and experts expect that body scanning may replace manual surveys completely in the future. 3D body scanning provides multiple benefits compared to the traditional set of one-dimensional anthropometric measures, since the complete 3D-shape of the subject is recorded and available for subsequent statistical analysis $[3,11]$.

In spite of these technological advances in anthropometrical data acquisition and scientific advances in processing 3D shape information, implementing these into product development processes is an open and challenging issue. This has several reasons:

- Lack of integration of 3D virtual design and 2D pattern construction: Design of garments is an highly creative task; appropriate virtual development tools are going to become available on an industrial base but are still object of ongoing research and development activities. Pattern design and construction is an highly technical task, requiring detailed know how on pattern construction principles and fit of garments. 
Today, this task typically is accomplished using 2D-CAD systems for pattern construction accompanied by physical fit test. Integrated solutions combining effectively and seamlessly both design and pattern construction on a more or less industrial basis are starting introduction into industry.

- Lack of comprehensive anthropometrical data and knowledge: Over decades apparel industry has developed pattern construction principles resulting from experienced perceptions of the human body supported by results from measurement surveys. In an increasingly growing global market availability of global anthropometric information has become a critical factor. Unfortunately, processing and interpretation of national survey reports, although mostly based on international standards, is an difficult task requiring advanced statistical and anthropometrical knowledge.

- Lack of solutions integrating anthropometry and product development: Systematic approaches are required to compare, relate and combined anthropometrical data originating from different sources. Although several approaches have been developed in the past years to provide electronic access and processing to both body dimensions and shape data, existing tools require advanced expertise and do only rarely reflect application specific aspects and often overburden the user [9].

iSize aims a new and different approach. To overcome the above burdens, iSize was designed and developed to (1) integrate anthropometrical data from different sources world wide in an standardized and structured way, (2) provide application specific analysis functionality taking background and way of thinking of the user into account and (3) provide a simple to use interface in an interactive online webportal allowing the user to perform fast and easy online analysis.

\section{Body scanning and anthropometric surveys}

Japan was probably the first country to use a 3D body scanner to conduct a large scale national size survey from 1992-1994. The Working Group of the CAESAR Project collected from 1998-2000 over 10.000 body scans in North America, the Netherlands and Italy and combined sitting and standing postures as well as a socio-demographic data. In the USA, England and the Netherlands the classic manual anthropometric measuring was combined with body scanning, in France and Sweden the last anthropometrical measuring campaigns were exclusively implemented by body scanners. In 2006 und 2007 further international measurement campaigns have been prepared and started (e.g. Germany, Spain, Romania, Thailand ...). In China a measurement study with for 1 Million Chinese people started with a pre-study on children (see figure 1).

Nevertheless, past results and anthropometrical knowledge from traditional studies form the basis for observations on anthropometrical changes in populations over long periods of time. Thus, comparability of 3D scan extracted measurements to traditional measurements is a fundamental issue for bridging between traditional one-dimensional anthropometry and 3D surface anthropometry methodologies.

Due to methodological differences in traditional measurement definition and 3D body scan extracted measurements and due to the previous lack of standardization methods, direct comparability of body measurements and scan extracted measurements on an individual basis is currently hard to achieve. Many of the traditional measurements are based on palpated body landmarks; this information is often not available in the 3D surface scans. Further many different postures are used in the traditional measurement process (e.g. ISO 7250 uses more than 10 different postures) while this is not practical in scanner based surveys. After all automatic measurement extraction routines can not unambiguously be defined on the basis of the standardized measurement definitions like in ISO 7250 or in ISO 8559 due to the lack of precise algorithmic descriptions [18-22]. 


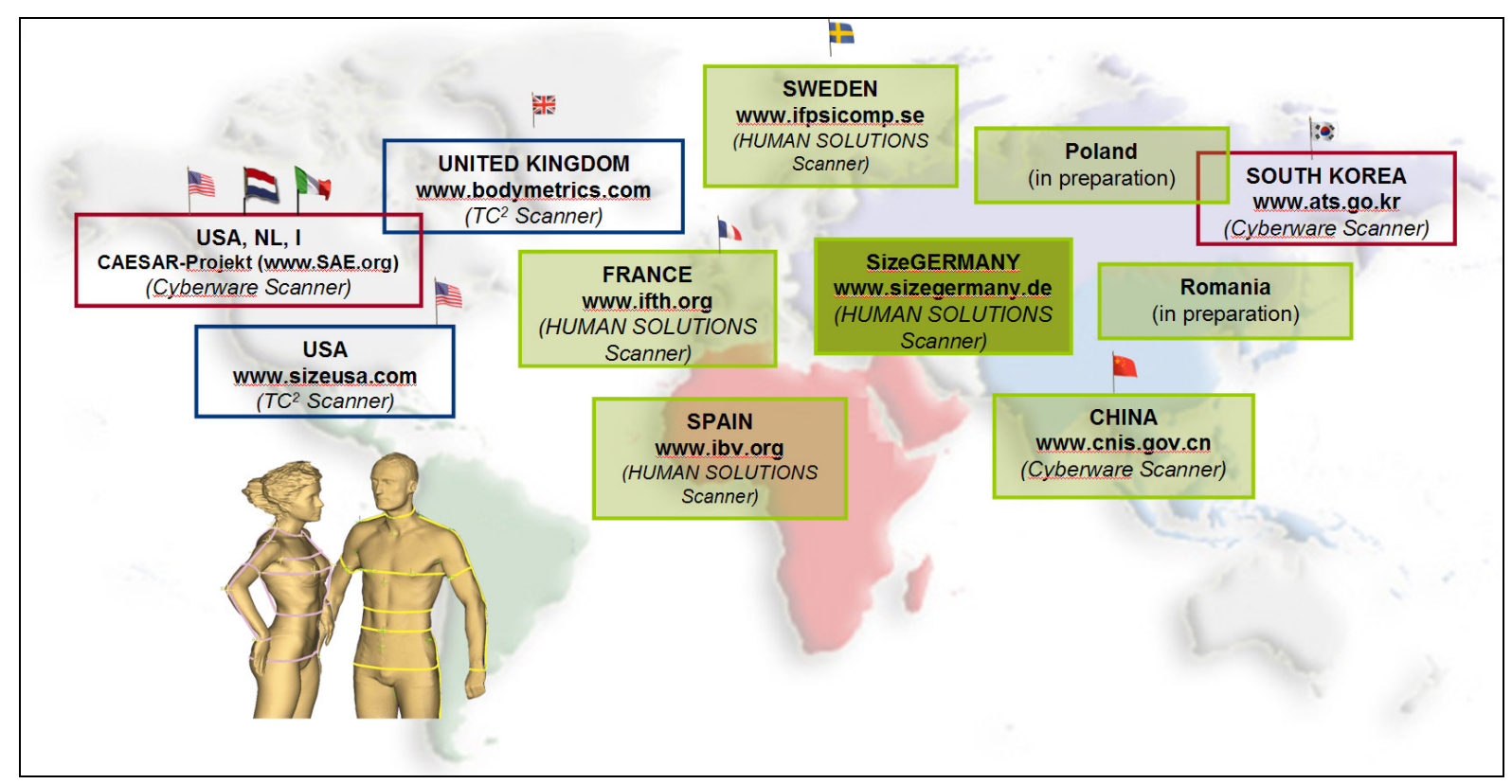

Fig. 1: The most important anthropometric measurement campaigns worldwide since 1998 [7]

Many countries already actualized their national apparel size tables as a result of those anthropometric size surveys but single companies often suffer because of some problems with the published results from other countries:

- It is time consuming and costly to find, access and analyze appropriate reliable data for design.

- Raw data often is not available for further and additional analysis, often only summary statistics are published

- The International sources of data are not always known

- Quality of data cannot be always be assured

- Analysis tools and knowledge of their appropriate use may be limited to a few experts

Carried out in Germany between September 2007 and February 2009, SizeGERMANY is the latest representative anthropometrical measurement survey of more than 13,000 men, women and children. At more than 30 measurement locations distributed across the country, complete three-dimensional body shape information and more than 80 body measurements were acquired using 3D body scanners.

The objective of the survey was to detect and document temporal changes of the body measurements and body proportions of men, women and children aged between 6 and 65+. Based on the results, updated body measurement statistics (ISO 7250-compliant) were acquired and an updated 3D man model for the CAD man model RAMSIS developed for the automotive industry. The apparel branch was provided with updated body measurement statistics (ISO 8559-compliant), adopted clothing size charts and recent market share information. These results also formed the basis for an updated secular growth prognosis model for German population, one which will last until 2040.

The project was implemented in close cooperation between Human Solutions and the Hohenstein Institutes. More than 100 companies from the apparel branch and five companies from the automotive industry took part in this undertaking - the largest sizing survey ever implemented in Germany.

One of the important innovative objectives of SizeGERMANY was to provide the partners with an Online Portal which would give them access to the survey data for the first time. Fast access to the results was not the only focal point, however - the companies also wanted to be able to analyze the data themselves, and use the results for their individual customers and products, providing participating companies access to results online, plus specific functionality for data analysis [6]. 


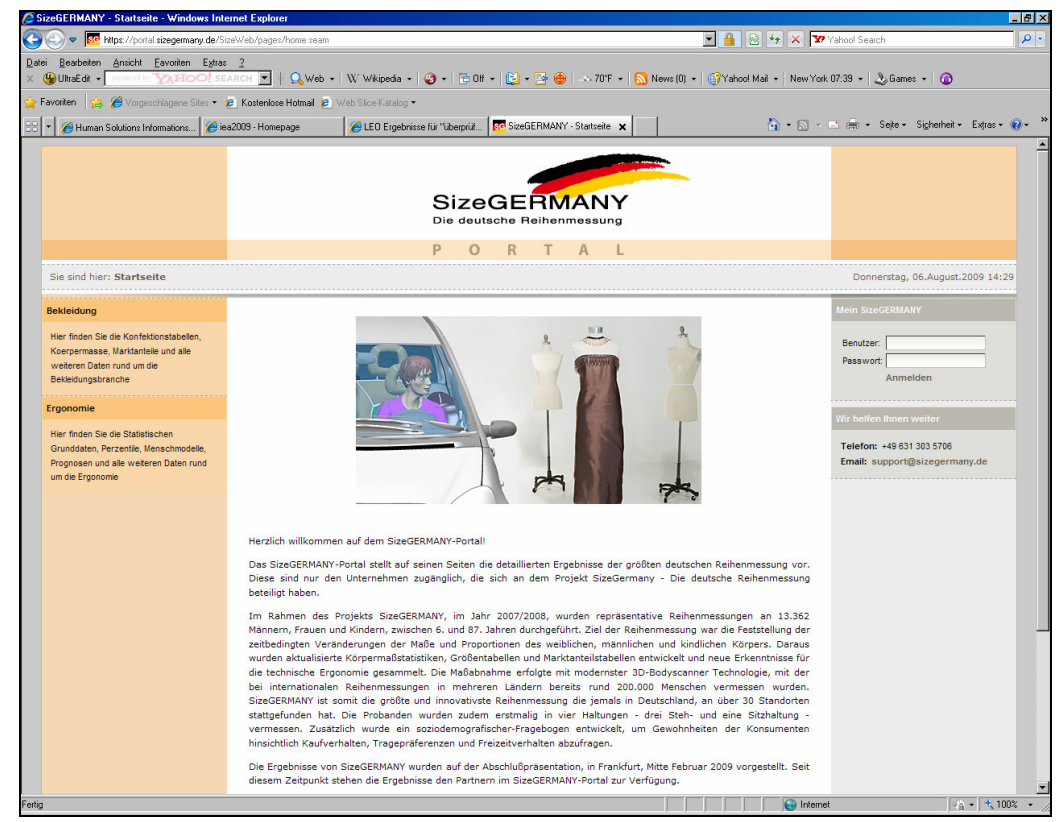

Fig. 2: The SizeGERMANY portal for analyzing anthropometric survey results

Human Solutions offered numerous training programs and support for the integration of this new technology into the apparel process chain. The use of the portal is positioned in the technical product development teams whose work always was to transform the results of sizing surveys into a new standard size table within their companies. Another emphasis on applications came up from the sales departments who were for the first time able to generate market data for company-specific target markets.

\section{SizeGERMANY is going global - The iSize-portal}

Most of the apparel companies who joint the SizeGERMANY-project are global actors on the Textile Market. And anyone who wants to open up new markets immediately encounters a major challenge and that is achieving correct fit.

Many apparel companies suffer from the lack of information about up-to-date body dimensions of their customers. The results are enormous return rates of catalog retailers, high discounts on garments which could not be sold on regular prices, high costs and delays in the product development process, risky and sometimes vague decisions when entering new markets and too often customers are unsatisfied by the lack of proper fitting sizes. The existing table of sizes must be ideal for current body dimensions in the target market. To identify the changes that are relevant for market success, most companies have so far used the years of experience gained from season to season.

Comparable information about body measurements, sizes and market shares in different countries are hard to find. Decisions for entering new sales markets are therefore often made more of feelings then of objective arguments.

The availability of actual information for the German target market within the SizeGERMANY portal naturally led to the requirement of comparable and standardized international survey results for global markets. Therefore Human solutions developed the iSize international online-portal as an enhancement on base of the positive experience and broad acceptance of the SizeGERMANY portal.

\section{1 iSize - The international anthropometric data portal}

iSize is a new and innovative web-based Sizing-Portal that combines worldwide body data with online analysis capabilities. iSize address both the apparel market as well as technical ergonomics. Since the way of applying anthropometrical data to optimally adopt fit of products is different, iSize provides basic and advanced functionality representing product development concepts in both areas. 


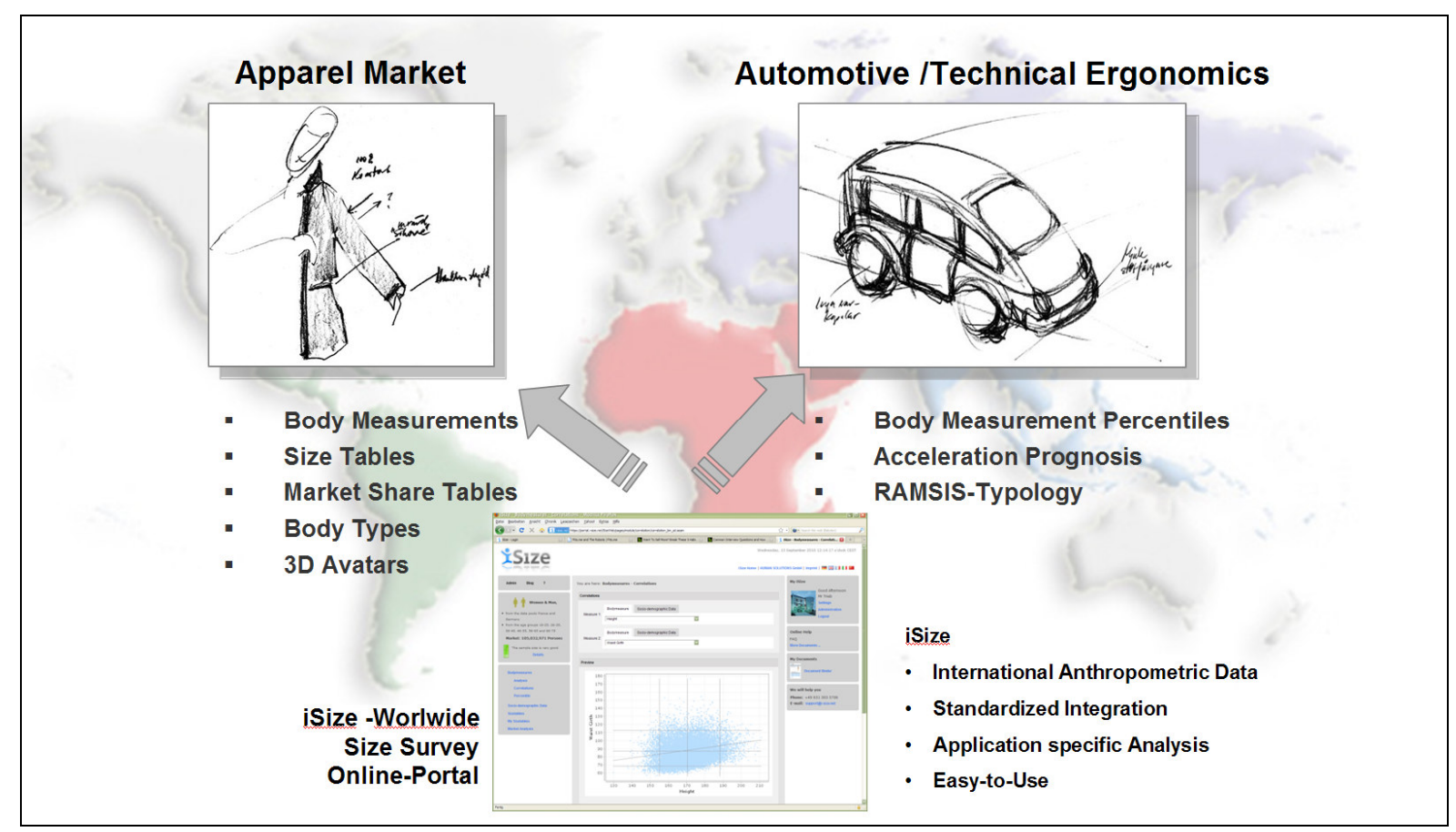

Fig. 3: iSize provides specific functionality for different markets on base of integrated international anthropometric survey data

iSize is providing companies with fast and easy access to the missing body dimensions of their target customer groups. Powerful functionality allows the user specifically from the apparel branch to evaluate market potentials, analyze the fit of their current sizing charts and optimize these for their target customers.

\subsection{Standardization in iSize}

Standardization of survey data is a key feature in order to reach comparability and combinability of anthropometrical data within one system. Thus iSize provides standardization for both standardized sozio-demographic data and the body measurement data.

- Sozio-demographic standardization: Sozio-demographic data is devided on a gender and age group base, which enables transnational combination of anthropometrical survey results taking additionally national official population statistics into account. The iSize standard provides nine different age groups from 6 to 75 years for females and males eachs. The iSize age group structure is summarized in the following table.

\begin{tabular}{c|c}
\hline Population & Age Groups \\
\hline \multirow{2}{*}{ Girls, Boys } & $6-10$ years \\
& $11-13$ years \\
& $14-17$ years \\
\hline & $18-25$ years \\
& $26-35$ years \\
Women, Men & $36-45$ years \\
& $46-55$ years \\
& $56-65$ years \\
& $66-75$ years \\
\hline
\end{tabular}

Fig. 4: Standardized age group structure in iSize 
- Body measurement standardization: Body measurements in iSize are strongly based on technical market standards to achieve highest degree of comparability and combinability. As a results iSize provides the following measurement sets:

Apparel measurement set: 44 measurements widely compliant with the ISO 8559 international standard for garment design [19]. These measurements are taken completely from a standard standing posture of the measured subjects.

\begin{tabular}{|c|l|l|l|l|}
\hline Nr. & Name & $\begin{array}{l}\text { Ref. to } \\
\text { Standard }\end{array}$ & Description \\
\hline 1 & Height & ISO 8559, 2.2.1 & $\begin{array}{l}\text { Vertical distance between the highest } \\
\text { detectable point of head and the ground with } \\
\text { upright body posture and closed legs }\end{array}$ \\
\hline 2 & Bust/Chest Girth & ISO 8559, 2.1.8 & $\begin{array}{l}\text { Maximally horizontal circumference measured } \\
\text { under the armpits and at the level of the } \\
\text { maximum projection of the bust / chest with } \\
\text { normal breathing }\end{array}$
\end{tabular}

Fig. 5: iSize body measurements for apparel, example 2 of 44 measurements

Ergonomic measurement set: 37 measurements compliant with the ISO 7250 international standard for technological design [18]. These measurements are taken partially from standing, sitting and functional postures of the measured subjects.

\begin{tabular}{|l|l|l|l|l|l|}
\hline $\begin{array}{c}\text { Body size } \\
\text { (Ergonomics) }\end{array}$ & $\begin{array}{c}\text { ISO } \\
\mathbf{7 2 5 0}\end{array}$ & $\begin{array}{l}\text { RAMSIS } \\
\text { measure }\end{array}$ & $\begin{array}{l}\text { Standard Posture I } \\
\text { measuring method }\end{array}$ & $\begin{array}{c}\text { Standard } \\
\text { measurement } \\
\text { definition }\end{array}$ & $\begin{array}{c}\text { Standard } \\
\text { measurement } \\
\text { drawing }\end{array}$ \\
\hline $\begin{array}{l}\text { Hip breadth, } \\
\text { standing }\end{array}$ & 4.1 .12 & $\begin{array}{l}\text { Subject stands erect } \\
\text { with feet together. } \\
\text { Measurement is } \\
\text { taken without press- } \\
\text { ing into the flesh of } \\
\text { the hips. }\end{array}$ & $\begin{array}{l}\text { Maximum hori- } \\
\text { zontal distance } \\
\text { across the hips. } \\
\text { See figure 11. }\end{array}$ \\
\hline $\begin{array}{l}\text { Sitting height } \\
\text { (erect) }\end{array}$ & 4.2 .01 & $\begin{array}{l}\text { Subject sits fully } \\
\text { erect with thighs fully } \\
\text { supported and lower } \\
\text { legs hanging freely. } \\
\text { Head is orientated in } \\
\text { the Frankfurt plane. }\end{array}$ & $\begin{array}{l}\text { Vertical distance } \\
\text { from a horizontal } \\
\text { sitting surface to } \\
\text { the highest point } \\
\text { of the head (ver- } \\
\text { tex). See figure } \\
12 .\end{array}$ \\
\hline
\end{tabular}

Fig. 6: iSize body measurements for technical Design, example 2 of 37 measurements

Additionaly, iSize provides a set of commonly used indices. This includes BMI (Body Mass Index), WTHR (Waist-to-Hip-Ratio) and Bust-to-Underbust-Difference which provide worthy information e.g. for figure type classification during design and optimization of size tables.

- Data representation standardization: iSize was developed to directly work on original sample data instead of approximations by continuous distribution functions. Whereas body measurements often are assumed to be normal distribution this is not true for most of the body measurements. Thus characterizing body measurement variation by mean and standard deviation or by percentiles (e.g. P5, P50, P95) leads to undesirable results and inaccuracies in statistical analysis. This is avoided by discrete sample data. 
- Population data standardization: Performing data analysis cross different age groups or combinations of different country populations, current populations sizes and portions are critical to the obtained results. Thus, current population and age group numbers of females and males has been integrated and associated with the measurement data in iSize.

\section{3 iSize - Easy-to-use User Interface}

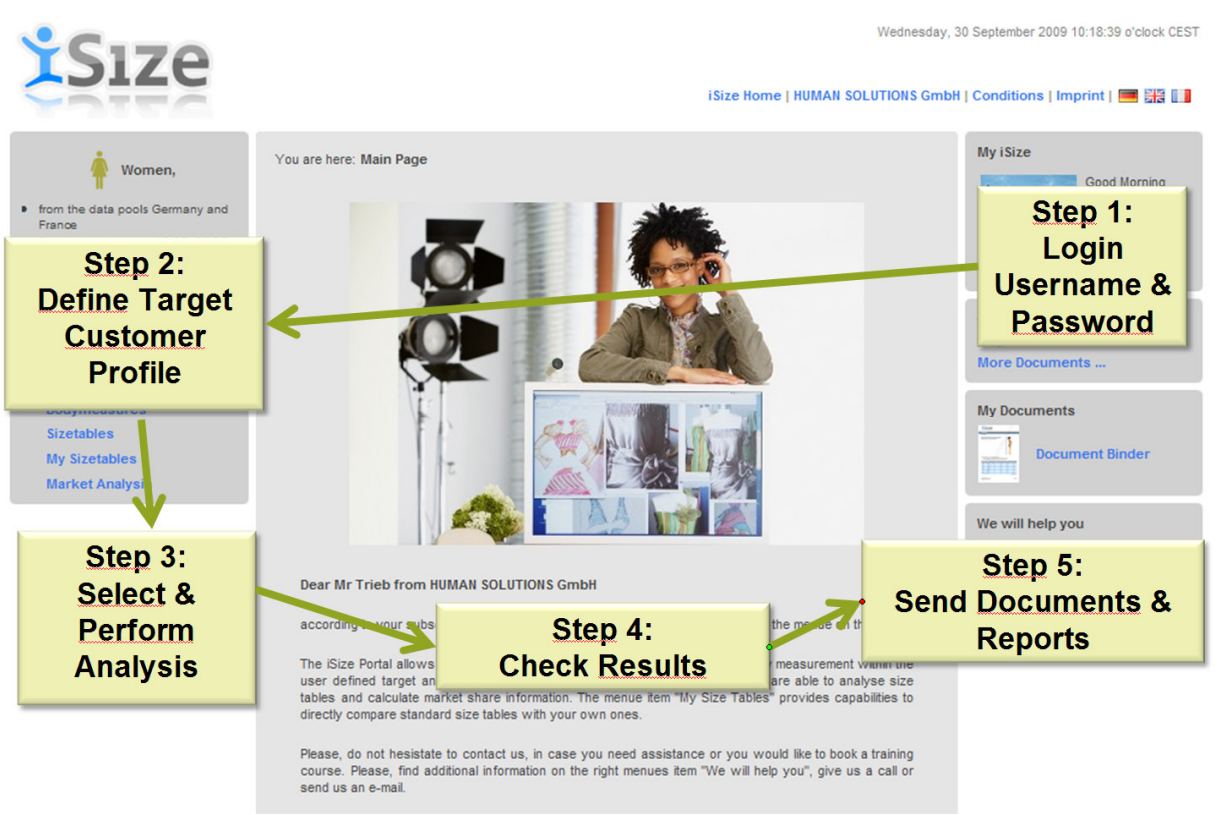

Fig. 7: iSize - User Interface and usage model of the online portal

\subsection{Functionality and typical analysis cases}

\section{Target Market Definition:}

Specific target market and customer focus groups can be selected either by choosing an individual country ore combining different markets to one group. This is very important for global acting apparel companies which normally do not create single size tables and fits for each different country. They can compare the analysis results of different countries or combined regions (e.g. Europe and Asia) just to decide which markets can be served with global or a local fit.

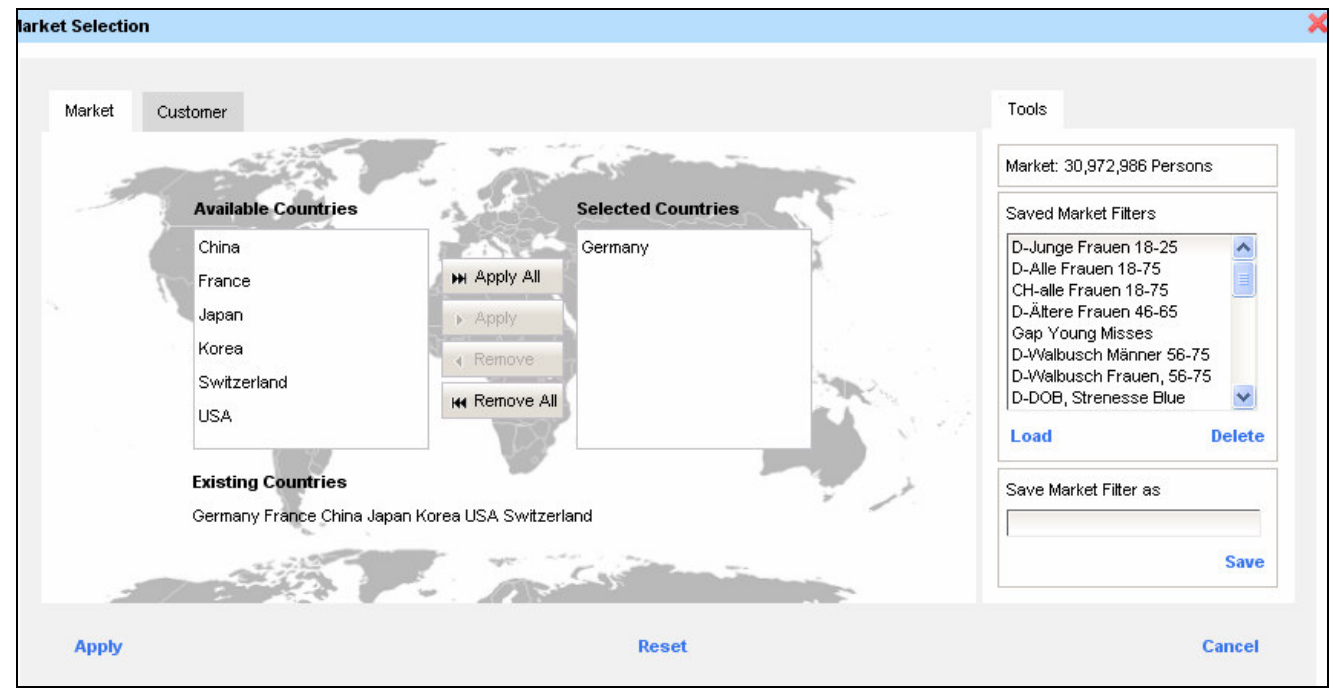

Fig. 8: Selection of target single ore combined target markets 
Additional target customer group selection allows selections or combined profiles for females, males, girls and boys. Nine pre-defined age groups $(6-10,11-13,14-17,18-25,26-35,36-45,46-55,56-65$ years) can be supplemented by socio-demographic filters (if available) and individually defined interesting ranges of body dimensions. This is very important for companies whose products often do not cover the complete range of body measurements but are addressed to a specific figure type (e.g. body height from 164 to $172 \mathrm{~cm}$ for women). For each subsequent analysis and optimization step they can exclude customers with body measurements that are not covered by the complete size range of their size table.

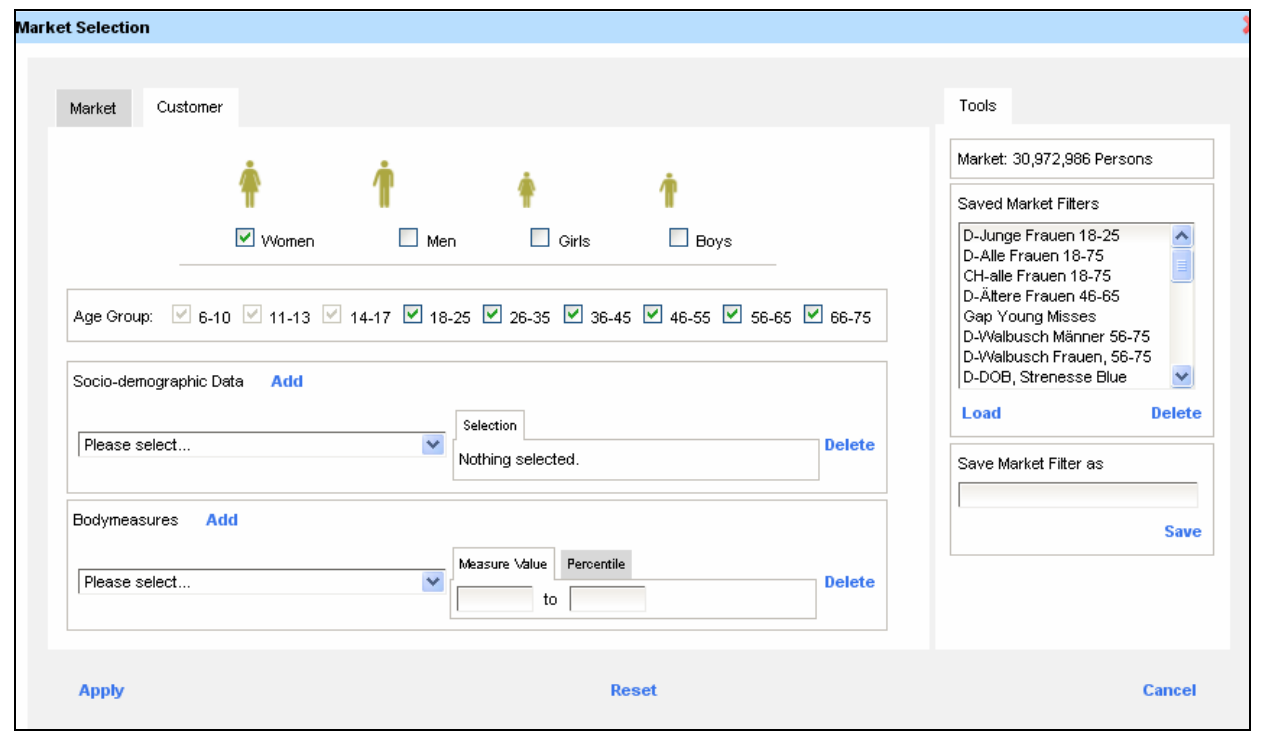

Fig. 9: Definitions of target customer on base of gender, age group, socio-demographic data and body measurements

Body Measurement Analysis: iSize allows numerous basic statistical analysis for the pre-defined customer focus groups (e.g. mean values, standard deviations, percentiles and distribution values and curves). 2-dimensional correlations between different body measurements or body measurements and socio-demographic data are building up the basis for a consistent grading.
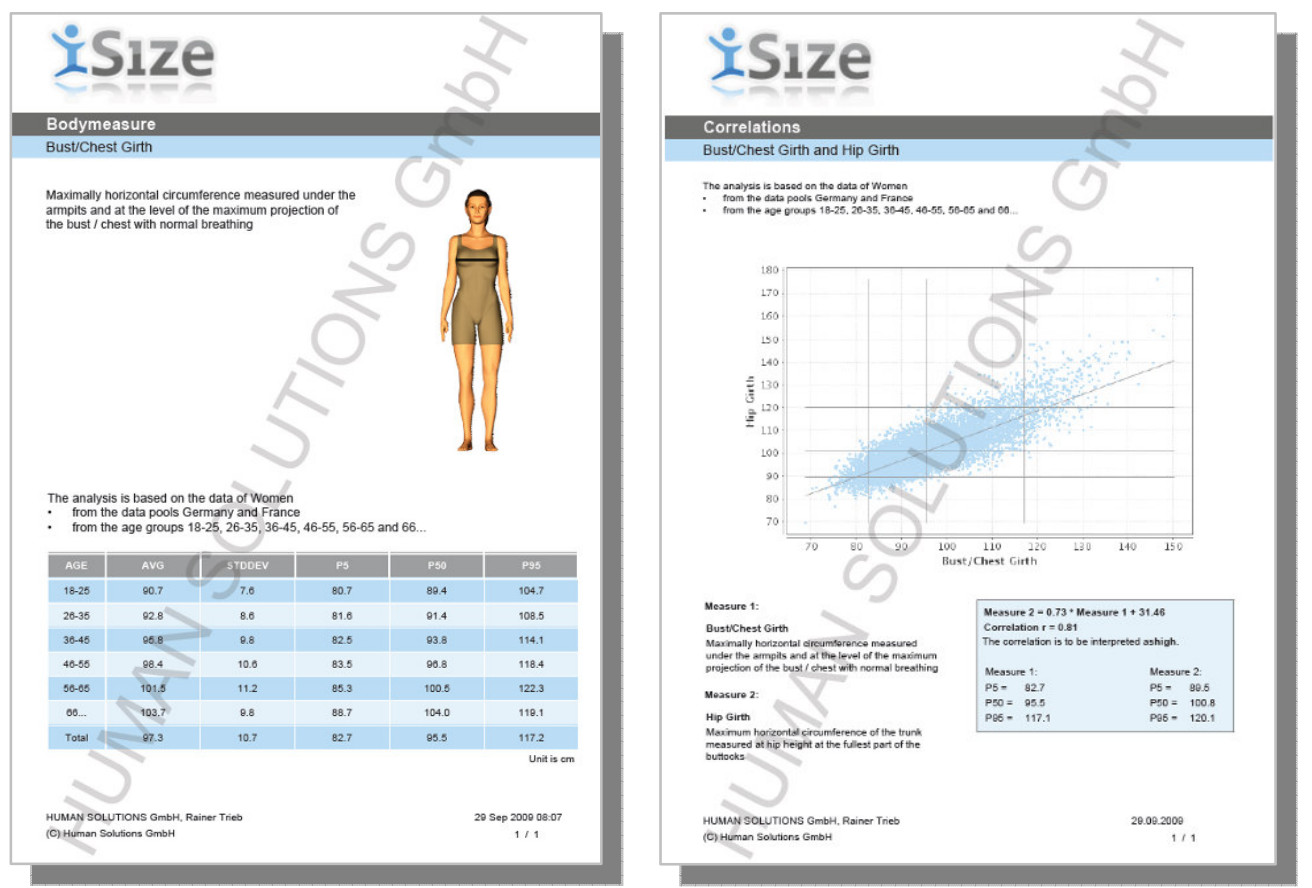

Fig. 10: Basic Statistical Analysis in iSize: a) one dimensional analysis and (b) correlation analysis of two measurements 
Market Share Analysis: Analyzing the markets shares for actual company size table on base of the individual customer focus groups in comparison to available standard size tables for different countries offers a good opportunity for critical reflections on the adaptations that have already been invented. Absolute market shares help to judge the actual coverage of the company market whereas relative market shares build the basis for general sizing decisions and for the optimization of size ranks especially within retail stores or online shops.

Optimization of company-specific size charts with respect to target customer groups: Companies can integrate their actual size charts and analyze their quality of coverage for their target customers. By simple adaptations of the primary body measurement correlations on base of a visual shifting the amendment of the actual market shares is displayed. After adapting the primary dimensions within a complete size table or for single sizes the best corresponding secondary dimensions are calculated automatically. Intermediate optimization steps are stored in a copy so that a hands-on and intuitive manipulation of the size charts is possible and in most cases successfully.
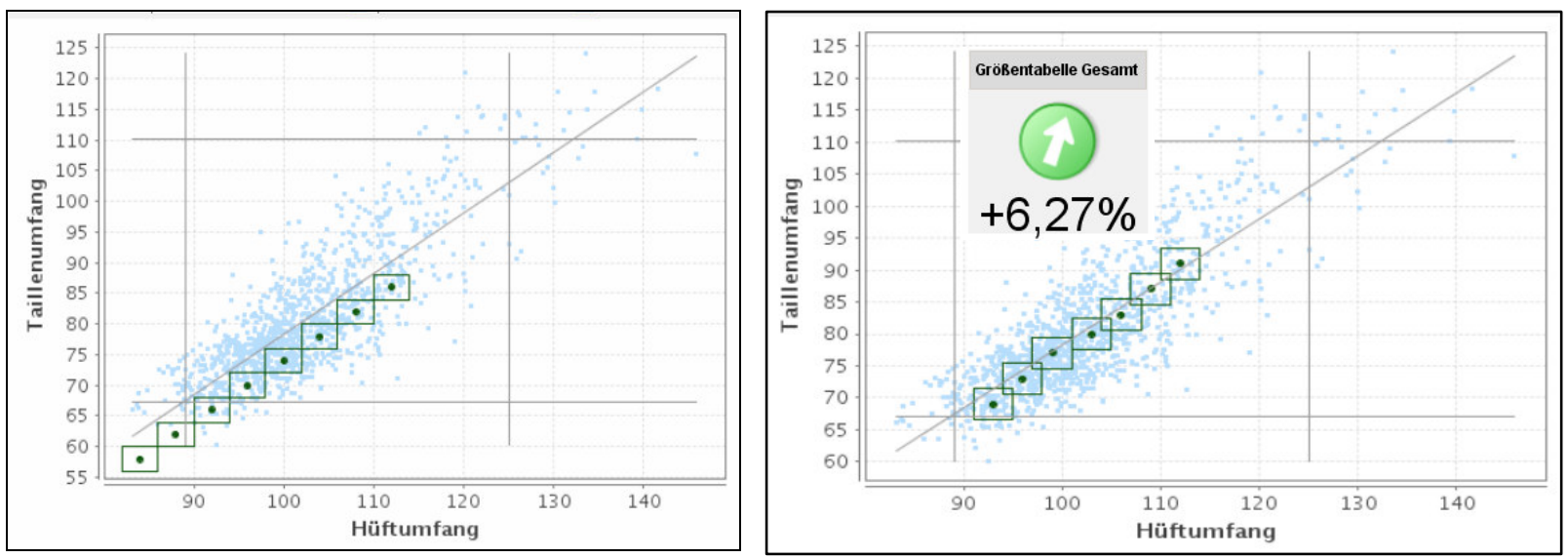

Fig. 11: Size chart optimization, before and after modification

Relabeling: The comparison of size charts with different body measurements and different grading steps is very complicated. For apparel companies that have to print the country-specific sizes on their labels is a daily requirement but not less complicated. Within iSize two size tables can be compared whereupon the differences between sizes and measurements are calculated. In that way it is much easier to find the best matches between the company specific sizes and the standard size charts used in foreign target markets. This function can be used in the future for relabeling the national sizes according to the developed European sizing standard within EN 13402 [14-17].

Central user management for company administrator: iSize offers an unlimited number of accounts of users within one company. The central administration of users can be taken over by the company itself. Username and Password is provided by a central administrator in the company, who also allocates the administration and the management of the access rights for each user. Optimized size charts as well as other analysis results can be checked by the administrator before publishing it company wide. 


\subsection{Integrated countries}

\begin{tabular}{|c|c|c|c|c|c|c|c|}
\hline \multirow[t]{2}{*}{ COUNTRY } & \multirow[b]{2}{*}{ Survey } & \multirow[b]{2}{*}{ Year of Survey } & \multirow[b]{2}{*}{ Age Group } & \multicolumn{2}{|c|}{ Number of Measured Subjects } & \multirow{2}{*}{$\begin{array}{l}\text { Measuring } \\
\text { Method }\end{array}$} & \multirow{2}{*}{$\begin{array}{c}\text { Data }{ }^{1)} \\
\text { accelerated }\end{array}$} \\
\hline & & & & FEMALE & MALE & & \\
\hline Germany & SiZEGERMANY & $2007-2008$ & $6-66+$ & 7.210 & 4.922 & 3D-Scan & no \\
\hline France & CNM 2006 & 2005-2006 & $5-70$ & 6.486 & 5.076 & 3D-Scan & no \\
\hline Korea & SizeKOREA & 2003-2004 & $18-70$ & 3.100 & 3.100 & Manual & no \\
\hline Japan & $\mathrm{HQL}$ & 1994 & $18-70$ & 3.000 & 3.000 & Manual & to 2008 \\
\hline China & GB10000-88 & $1985-1988$ & $\begin{array}{c}16-60 \mathrm{~m} \\
18-55 \mathrm{f}\end{array}$ & 11.150 & 11.164 & Manual & to 2008 \\
\hline USA & NHANES III & 1990 & $18-70$ & 7.806 & 6.821 & Manual & to 2008 \\
\hline
\end{tabular}

$\begin{array}{ll}\text { CNM } & \text { Campagne Nationale de Mensuration } \\ \text { NHANES III } & \text { National Health and Nutrition Estimation Survey } \\ \text { HQL } & \text { Research Institute of Human Engineering for Quality of Life } \\ \text { GB10000-88 } & \text { Chinese Standard, China National Technical Committee for the Standardization Of Ergonomics (CNTCSE) }\end{array}$

Data accelerated ${ }^{13} \quad$ Survey cata from before 2000 has been accelerated, i.e. scaled up to reference year 2008 to achieve meaningfull comparability. Based on the knwoledge about the change of body measurements over time a prognosis model was applied to the survey data.

Fig. 12: iSize - Currently integrated countries

\subsection{Who benefits from iSize?}

iSize addresses the needs of various responsibilities and offers great benefits for different target groups across the entire apparel company:

Management and Decision Makers are mainly interested in a faster expanding into new markets with less risk. A definite forecast also for new markets promises less stock and offers cost savings potentials in the whole production process chain.

Sales and marketing departments are mainly interested in increasing sales in combination with lower returns and in a better forecast for new markets. A better fit creates satisfied customers who will develop a better goodwill to the brand. Additionally they will enlarge their knowledge about target customer groups what helps them to channel effective and customer focused marketing campaigns.

Product Development teams will save time by faster development circles and improving the quality of their decisions in alterations - often for the first time fite can be improved on a quantitative base. Changes and varieties of customer shapes and measurements are known so that the adoption of basic patterns to real body shapes can be optimized. The sample of the right sizes for the individual target customers and markets is maintained. Further on iSize supports the selection of the correct house model for try-on and fitting sessions.

Retailors: Retailers are mainly interested in focusing on the right customer, especially on having the right sizes in the shop. This can help to improve the customer satisfaction and enlarge the turnover. Analysis with iSize can beyond that facilitate developing and/or improving e-commerce services.

\section{Future prospects for worldwide sizing and fit optimization}

Today the complete textile supply chain is confronted with an ever-increasing number of collections to markets in ever-decreasing time frames. 3D pattern design and a virtualized product development process provide answers for rethinking processes and gradually carrying more steps out digitally related by saves of time and money. 3D CAD systems can reduce frustrating and cost-intensive iterations between design, pattern making, sample production and try-on sessions with fit models or on physical manikins [4]. But how can iSize be integrated into this new process chain of virtual product development? 


\subsection{The future process chain for International Sizing in Apparel}

In the first step, the target group and product-relevant data is determined in an iSize online Portal. In the second step the CAD system uses this data for cut modifications and grading. The third step sees the trying-on of the new garment on virtual models of the new target group.

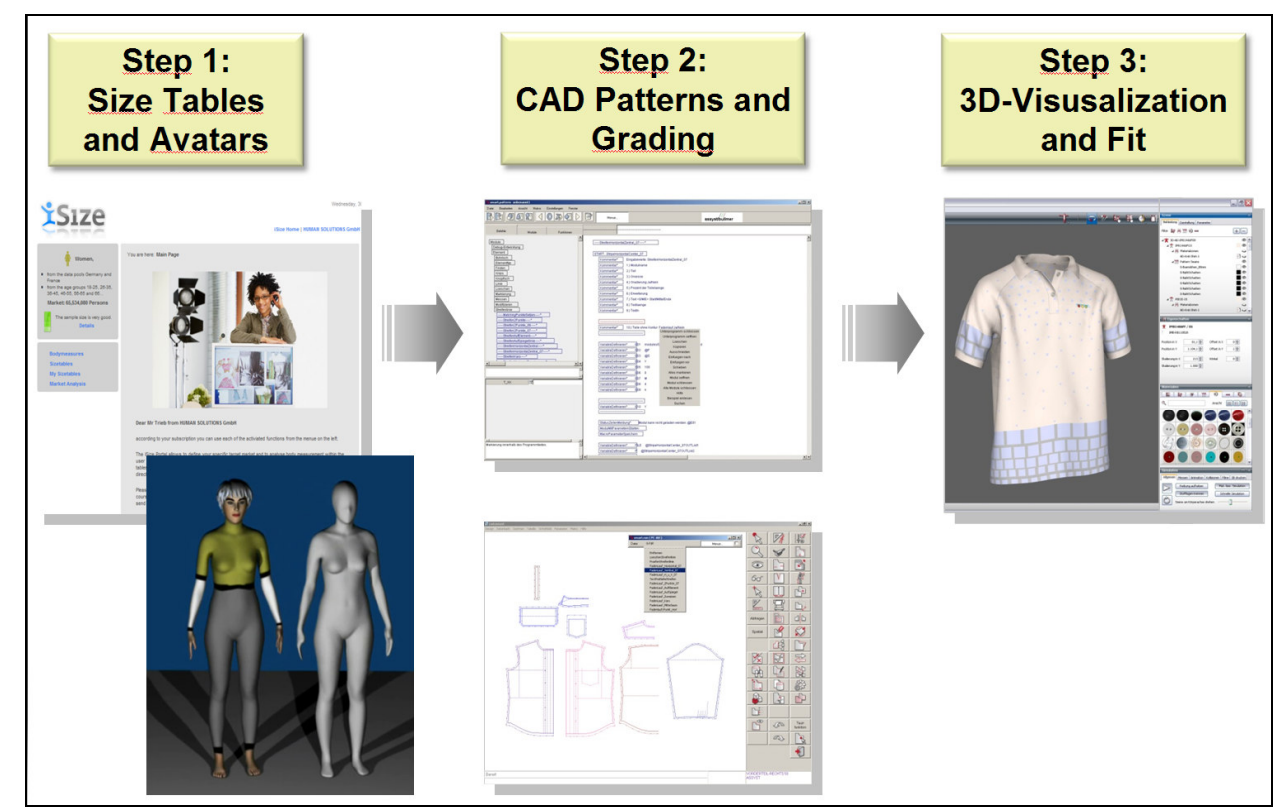

Fig. 13: Future process within the process chain for virtual product development and fit optimization

The data quality and analysis options of the iSize portal have actually changed the meaning of the words body dimensions and size tables. The portal has expanded the database for pattern creation by one essential element: 3D body shapes. The supplementing of the classic 2D cuts add-ons with volume information brings two amazing facts to light:

1. Two test persons can actually have the same standard size according to the table of sizes - but they have completely different fit requirements [10].

2. Body shapes can be grouped in specific regional or age-related figure types.

From an economic standpoint, this finding has a massive impact on the apparel industry. Anyone who wants to open up new markets immediately encounters a major challenge - and that is achieving correct fit. The existing table of sizes must be ideal for current body dimensions in the target market, so basic patterns and model patterns have to be adapted to the new size tables. Grading must also be created anew. To identify the changes that are relevant for market success, most companies have so far used the years of experience gained from season to season.

This process was time-consuming and protracted - now, however, thanks to the seamless availability of real body dimensions and new tables of sizes in 2D and 3D, cut modifications can be implemented significantly faster and much more easily.

Manufacturers are thus optimally prepared should they wish to open up additional age-group segments, new regional markets or even more product segments. From the first day on, they are able to offer their customers optimal fit - and this secures valuable market shares even in the first season.

How it works in iSize? In the first step, the target group and product-relevant data is determined in the iSize portal and a Scanatar with corresponding sizes is generated. In the second step, the CAD system uses this data for cut modifications and grading. The third step sees the trying-on of the new garment on virtual models (Scanatars) of the new target group. 


\subsection{Combining 2D-Size Tables, 3D-Scanatars and 3D-Virtualisation - a case study}

Assuming that a German apparel company wants to offer ladies' wear products on the chinese market. The product in question - ladies' pants in sizes that are commensurate with the German ladies' wear table [1].

\section{Defining the target market and target group}

Within iSize "China" is first selected as the target market. Then the customer target profile is selected by gender, in this case, female and age, in this case between 18 and 75. For ladies' pants with China as the target market it is first of all necessary to look at the waist-to-hip proportions and the length dimensions. Thanks to the overlaying of the target customer dimensions on the selected customer specific or standard size table iSize shows that the German table of sizes is not suitable for the Chinese market.

\section{Optimizing the sizes table for the Chinese market}

By simply step-by-step adapting the entire serial sizes or individual sizes interactively to the target market, iSize creates interactively an optimized new size table which optimally fits to the body dimensions of the target market.

\section{Calculating market potential}

For pants with China as the target market, the waist circumference, the hip circumference and the internal leg length are chosen as primary dimensions for calculating the market share. To determine the market potential, the absolute and relative market shares are calculated.

\section{Exporting the optimized size table}

The analysis results are saved in the user's private document area. From there each analyzis can be export the results in a standardized format. The exported table of sizes contains the body dimension values for each size. These values can be transferred to a CAD system for implementation into a cut. In the future grading will be adapted automatically based on the automated size table and with respect to the existing grading rules.

\section{Creating a mid-range body shape and Scanatars}

The quality of garment fit in processes using virtual simulation technologies is driven by many parameters. Obviously, a simulation engine is necessary that is capable of addressing material parameters, all types of seams and calculating multiple layers of garments in an acceptable timeframe. There is high demand on the performance to use it in industrial day-to-day work. Second, the availability of patterns is key factor. All details of the garments must be known in order to result in a realistic simulation. That is achieved by hooking up a professional CAD system that manages all the information to the simulation engine. Unfortunately, the third aspect is very often underestimated: In particularly realistic body shapes are crucial on which the garments are tested on. Most simulation engines work with artificial human bodies that fulfill more aesthetic aspects than requirements related to correct body proportions, dimensions and 3D shape.

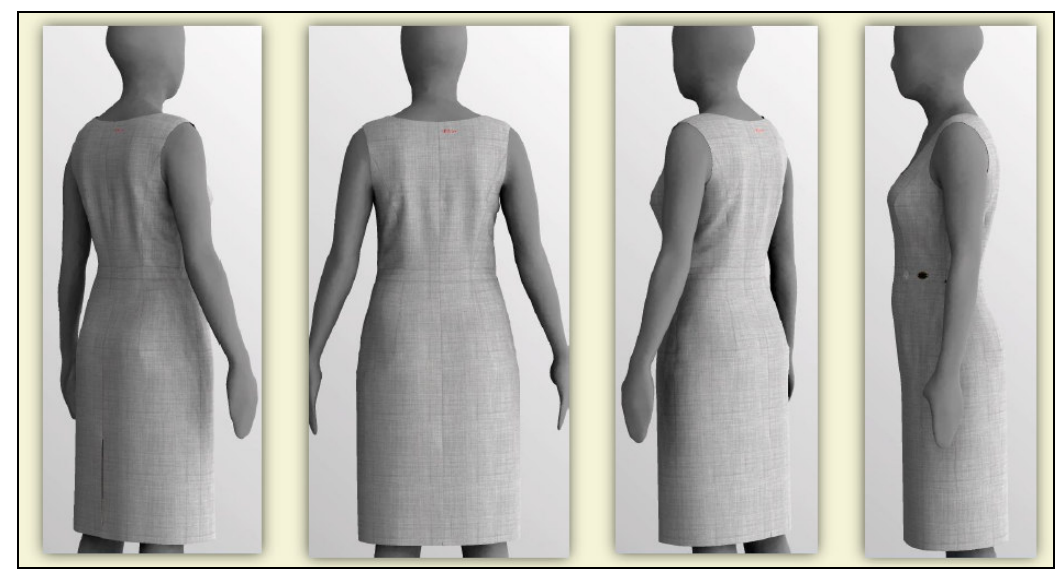

Fig. 14: 3D simulation on a realistic Scanatar representing the German ladies standard size 38 
Human Solutions developed a technology that turns a 3-D body scan not only into an avatar but into a "Scanatar". As apposed to an avatar a Scanatar features the exact body measurements and shape of a real individual. Alternatively, a Scanatar can be the representation of a standard size of standardized size tables or in-house models - also with exact body dimensions and realistic shape information.

All the 3D scans - which primary body measurements are covered by a company specific or a standard size table - are selected, using the primary dimensions and tolerance areas of the clothing table. iSize automatically creates a mid-range, representative 3D body shape from the scans. If required, the body shape can also be adapted to target measurements. This Scanatar can now be exported to tools for $3 \mathrm{D}$ visualization and simulation where you can use a realistic virtual model to try on the garment and evaluate its appearance and proportions.

\section{References}

1. Rissiek, A.: "Morgen verkaufen wir auch in Asien! Strategien und Lösungen zur Optimierung von Marktpotenzial und Passform für internationale Märkte“. FashionForum, Munich, 2009

2. Trieb, R.: "iSize-The international Sizing Portal for Garment Design"; WEAR Conference 2010 Antropometry applied to product innovation, Valencia, September 22-23, 2010

3. Trieb, R.; Seidl, A.; Gordon, C. ; Bradtmiller, B.; Corner, B. D.; Paquette, S. P.: "Comparability of 3D Scan Extracted Measurements and Traditional Measurements - A practical application of the ISO 20685 Standard." IEA 2009, Bejing.

4. Seidl, A.: "The real thing - The future of 3D modelling and pattern design." IACDE Conference, Venice, Italy, October 2010

5. Balzulat, J.; Seebauer, W.: "Made-to-Measure Garments in 3-D." Proceedings of 3D Body Scanning Conference, Lugano, Switzerland, October 2010

6. Seidl, A,; Trieb, R.; Wirsching, H.-J.: "SizeGERMANY - the new German Anthropometric Survey. Conceptual Design, Implementation and Results." IEA 2009, Bejing

7. Trieb, R.; Seidl, A.; Rissiek, A; Wirsching, H.-J.: „Weltweite anthropometrische Reihenmessungen mit BodyScanning - Überblick über die wichtigsten Projekte, Verfahren und Ergebnisse“, 54. GfA Frühjahrskongress, 9.-11. April 2008, München (Falkultät Maschinenwesen, TU München in Garching)

8. Petrova, A.: "Creating sizing systems." In: Sizing in clothing. Developing effective sizing systems for ready-to-wear clothing. Woodhead Publishing Limited, 2007, page 57-87.

9. WEAR - Word Engineering Anthropometric Resource. Flyer. http://ovrt.nist.gov/projects/wear.

10. Ashdown, S.; Loker, S.; Rucker, M.: "Improved Apparel Sizing: Fit and Anthropometric 3D Scan Data", NTC Project: S04-CR01; National Textile Center Research Briefs, June 2007

11. Trieb, R.; Seidl, A.; Hansen, G.: "3-D Body Scanning for Mass Customized Products -Solutions and Applications", Numerisation 2000 - Scanning 2000; 24.-25. May 2000; Paris, France

12. Yu, W.: "Human anthropometrics and sizing systems." In: Clothing appearance and fit - Science and technology. Woodhead Publishing Limited, 2000, page 169-195.

13. DIN 33402 (1978): „Körpermaße des Menschen“. Part 1 - 3.

14. EN 13402-1 (2001-06). "Size designation of clothes - Part 1: Terms, definitions and body measurement procedure" (ISO 3635:1981, modified); German version EN 13402-1:2001

15. EN 13402-2 (2002-09): "Size designation of clothes - Part 2: Primary and secondary dimensions".

16. EN 13402-3 (2005-04): "Size designation of clothes - Part 3: Measurements and intervals".

17. OENORM EN 13402-4 (2005-05): "Größenbezeichnung von Bekleidung - Teil 4: Codierungssystem"

18. ISO 7250:1996: "Basic human body measurements for technological design".

19. ISO 8559:1989: "Garment construction and anthropometric surveys -- Body dimensions".

20. ISO 20685:2006: "3D scanning methodologies for internationally compatible anthropometric data-bases"

21. ISO 15535:2003: "General requirements for establishing anthropometric databases".

22. ISO 15537:2004: "Principles for selecting and using test persons for testing anthropometric aspects of industrial products and designs". 